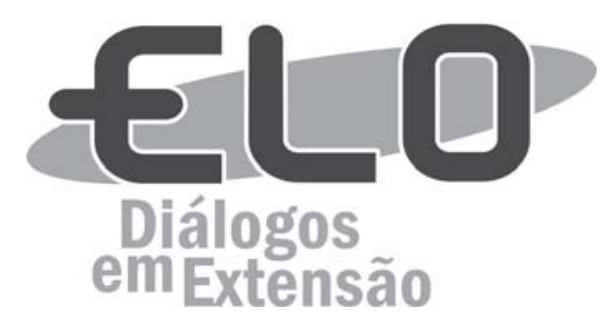

\title{
Formação Continuada de professores de Ciências e Biologia no litoral do Paraná: relato de experiência
}

\author{
Everaldo dos Santos ${ }^{1}$, Izabel Carolina Raittz Cavallet ${ }^{2}$, \\ Leandro Angelo Pereira ${ }^{3}$, Caroline Dorada Pereira Portela 4
}

\begin{abstract}
Resumo: O processo de formação continuada de professores é fundamental para a efetivação de um currículo que seja adequado às realidades locais e regionais, dessa forma, o projeto de extensão promovido pelo IFPR Campus Paranaguá - em 2012 e 2014 teve como objetivo a oferta de oficinas para promover a formação continuada dos professores de Ciências e Biologia da rede pública de ensino do estado do Paraná do Núcleo Regional de Paranaguá, a partir da experiência dos docentes e estudantes do Campus Paranaguá do IFPR. Para isso, foram ofertadas duas oficinas para professores dos diferentes municípios do litoral do Paraná, sendo uma de Ciência no Cinema e outra de Experimentação em Ciências. As inscrições e participações foram oportunizadas pelo Núcleo Regional de Educação do Paraná - Paranaguá (NRE). Com o relato desta experiência de extensão foi possível perceber que o projeto oportunizou o intercâmbio de práticas e conhecimentos entre os professores da rede pública. Além disso, foi possivel diagnosticar a carência de oferta desses cursos de formação continuada na região litorânea do Paraná e o potencial de mudança de práticas pedagógicas de acordo com as realidades locais no litoral do Paraná.
\end{abstract}

Palavras-chave: Formação continuada. Ensino de Ciências. Ensino de Biologia. Extensão.

Área Temática: Educação.

\section{Continuing Education of the Science education and Biology teachers on the coast of Paraná: experience report}

\begin{abstract}
The process of continuous teacher training is fundamental to the realization of a curriculum that is appropriate to local and regional realities. In this way, the extension project promoted by IFPR Campus Paranaguá in 2012 and 2014 had the objective of offering workshops to promote the continuing education of Science and Biology teachers in the Paraná state public school of the Paranaguá Regional Nucleus, based on the experience of the teachers and students of the Campus Paranagua of the IFPR. For this, two workshops were offered for teachers from the different municipalities of the coast of Paraná, one of Science in Cinema and another one of Experimentation in Sciences. The registrations and participation were given by the Regional Education Center of Paraná - Paranaguá (NRE). With the report of this experience of extension it was possible to perceive that the project facilitated the exchange of practices and knowledge among the teachers of the public network. In addition, it is possible to diagnose the lack of supply of these continuing education courses in the coastal region of Paraná and the potential of changing pedagogical practices according to the local realities in the coast of Paraná.
\end{abstract}

Keywords: Continuing education. Science teaching. Teaching of Biology. Extension.

\footnotetext{
${ }^{1}$ Biólogo, doutor em Engenharia Florestal e professor do IFPR - Campus Paranaguá E-mail: everaldo.santos@ifpr.edu.br

${ }^{2}$ Médica veterinária, doutoranda em Medicina Veterinária e professora do IFPR - Campus Paranaguá E-mail: izabel.cavallet@ifpr.edu.br

${ }^{3}$ Biólogo, doutor em Ecologia e Conservação e professor do IFPR - Campus Paranaguá E-mail: leandro.pereira@ifpr.edu.br

${ }^{4}$ Licenciada em Física, mestre em educação e professora do IFPR - Campus Paranaguá E-mail: caroline.portela@ifpr.edu.br
} 


\section{Formación continua de profesores de Ciencias y Biología en el litoral de Paraná: relato de experiencia}

Resumen: El proceso de formación continuada de profesores es fundamental para la efectividad de un currículo que sea adecuado a las realidades locales y regionales, de esta forma, el proyecto de extensión promovido por el IFPR Campus Paranaguá en 2012 y 2014 tuvo como objetivo la oferta de talleres para promover la formación continuada de los profesores de Ciencias y Biología de la red pública de enseñanza del estado de Paraná del Núcleo Regional de Paranaguá, a partir de la experiencia de los docentes y estudiantes del Campus Paranaguá del IFPR. Para ello, se ofrecieron dos talleres para profesores de los diferentes municipios del litoral del Paraná, siendo una de Ciencia en el Cine y otra de Experimentación en Ciencias. Las inscripciones y participaciones fueron oportunizadas por el Núcleo Regional de Educación de Paraná - Paranaguá (NRE). Con el relato de esta experiencia de extensión fue posible percibir que el proyecto oportunizó el intercambio de prácticas y conocimientos entre los profesores de la red pública. Además, se puede diagnosticar la carencia de oferta de estos cursos de formación continuada en la región costera del Paraná y el potencial de cambio de prácticas pedagógicas de acuerdo con las realidades locales en el litoral del Paraná.

Palabras clave: Formación continua. Enseñanza de Ciencias. Enseñanza de Biología. Extensión.

\section{Introdução}

Os professores de Ciências do Ensino Fundamental e Biologia do Ensino Médio encontram, de modo geral, dificuldades para trabalhar o conhecimento científico a partir da abordagem histórica e filosófica da Ciência com conteúdos científicos didatizados e contextualizados a partir da realidade dos estudantes. Devido aos diferentes obstáculos que se apresentam na prática docente (MARTINS, 2007). Essas dificuldades podem ser, tanto conceituais como metodológicas causadas por deficiências na formação inicial e continuada conforme apontamento de alguns pesquisadores, ou falta de condições de trabalho e investimentos em formação continuada. Sendo assim, o projeto de extensão intitulado formação continuada de docentes de Ciências e Biologia oportunizou a oferta de oficinas presenciais para promover a troca de experiências e conhecimentos entre professores de Ciências e Biologia de seis municípios do litoral do Paraná em dois diferentes momentos nos anos de 2012 e 2014.

As oficinas foram ofertadas a partir de outras iniciativas ou projetos, como por exemplo, o Ciência no Cinema e a Experimentoteca Ambiental que já estavam sendo desenvolvidos por estudantes do Instituto Federal do Paraná (IFPR) - Campus Paranaguá. Além disso, a proposta de extensão procurou aproximar a comunidade interna do Campus Paranaguá do IFPR com as diferentes realidades das comunidades do litoral paranaense por meio de troca de experiências entre os professores envolvidos e os estudantes da instituição. A intenção foi melhorar o entendimento da realidade histórica e cultural a respeito do ensino formal de Ciências e Biologia na região litorânea. De maneira que fosse levantado subsídios para discussão e posterior melhoria da compreensão da realidade local e possíveis adaptações em ofertas futuras de cursos de extensão.

A primeira oficina, Ciência no cinema, buscou mostrar possibilidades de abordagem a respeito da construção do conhecimento científico e tecnológico na relação entre ensino e aprendizagem de Ciências e Biologia. Além da valorização de aspectos da epistemologia da Ciência, abordando os pressupostos filosóficos e sociais da construção da Ciência, mostrando como é possível abordar a natureza da Ciência a partir de recursos cinematográficos com estudantes da Educação Básica.

Dessa forma, o cinema mostra-se bastante interessante como recurso didático, podendo servir para problematização e contextualização de conceitos científicos. Há pesquisas que indicam a sua utilização por professores com possibilidade de discussão a respeito da natureza da Ciência. Pois, Bonotto (2010) ao investigar possibilidades de exploração didática a partir de recursos cinematográficos, chama a atenção para utilização de filmes não somente como suporte didático de conteúdos específicos mas também para inserir discussões a respeito da análise crítica sobre a própria produção científica e a vida dos cientistas. Cachapuz, et. al (2004) enfatizam que a aquisição de conhecimentos científicos não leva necessariamente à compreensão de como a Ciência funciona, por isso é fundamental que os professores de Ciências e Biologia não apenas trabalhem a construção do conhecimento científico, mas proponham atividades que vão além e possibilitem o entendimento de como a Ciência é construída historicamente. Os filmes podem auxiliar na promoção de problematizações a respeito de conteúdos e temas científicos e tecnológicos mas também no entendimento no processo de construção do 
conhecimento científico (SCHEID, 2008; TAVARES, 2009; LOUREIRO, 2008). Tendo isso, Duarte e Alegria (2008) propõem uma reflexão sobre as relações entre educação e cinema no Brasil, enfocando a inserção de filmes em projetos educativos.

Quanto a segunda oficina, de experimentação no ensino de Ciências, intitulado oficina de experimentação ambiental e que objetivou a abordagem de problematizações e contextualizações para construção de conceitos científicos. Os professores participantes planejaram e executaram experimentos aplicáveis ao ensino de Ciências e Biologia. Onde se considera que os experimentos fazem parte dos processos de ensino e aprendizagem em Ciências Naturais (PACHECO, 1997). Galiazzi e Gonçalves (2004), entendem que a incorporação de atividades experimentais no ensino das disciplinas científicas pode aproximar o estudante da forma como se produz o conhecimento científico. Além disso, a apropriação e utilização de instrumentos e metodologias científicas podem ajudar no aprimoramento do discurso das Ciências, e como tal, ser incorporado no ambiente científico da escola, a fim de permitir a enculturação de alunos e professores (FIGUEIREDO, 2017).

Desta forma, foram ofertadas as oficinas oportunizando o uso de espaços do IFPR - Campus Paranaguá como os laboratórios, o auditório além de espaços externos para atividades de campo com auxílio dos estudantes bolsistas do projeto de extensão e estudantes com bolsas de programas sociais (PBIS). Neste contexto, o curso de extensão teve como objetivo a oferta de oficinas para promover a formação continuada dos professores de Ciências e Biologia da rede pública de ensino do estado do Paraná do Núcleo Regional de Paranaguá, a partir da experiência dos docentes e estudantes do Campus Paranaguá do IFPR.

\section{Metodologia}

No mês de novembro de 2012 e 2014 foram ofertadas duas oficinas em cada ano que integraram um curso de extensão em formação continuada de professores de Ciências e Biologia. Ofertado aos professores da região litorânea do Paraná pelo Instituto Federal do Paraná Campus Paranaguá. Em 2012 o curso teve 30 inscritos e 23 certificados e em 2014 o curso foi ofertado a 42 professores participantes com certificação conjunta entre o IFPR e o Núcleo Regional de Educação de Paranaguá (NRE).

Uma das oficinas ofertadas foi Ciência no Cinema, que era um subprojeto desenvolvido pelos estudantes estagiários do IFPR. Onde foram trabalhados alguns referenciais teóricos sobre o uso de cinema para abordar o tema Ciência. E a segunda oficina de Experimentoteca, na qual foram propostos experimentos que já estavam sendo desenvolvidos nos laboratórios do Campus Paranaguá com experimentos gerais para abordar temas como fotossíntese e reações bioquímicas nas células. Bem como uma atividade de campo que envolveu experimentação com coleta, extração e identificação de fauna do solo, além da aquaponia.

Quanto à primeira oficina ofertada, foi construído um roteiro coletivamente entre os professores a partir dos dois filmes selecionados pelo grupo na oficina. Os filmes foram projetados e discutidos a partir do roteiro previamente elaborado considerando abordagem do tema principal dos filmes, contextos e/ou conteúdos específicos que poderiam ser trabalhados em Ciências e Biologia. Então, os professores exercitaram a metodologia construindo o roteiro e assistiram os filmes para exercitar a aplicação deste roteiro com seus alunos no contexto da sua realidade local e cultural.

O encaminhamento metodológico da oficina Experimentoteca foi similar ao da construção dos roteiros e seleção dos possíveis experimentos práticos que já estavam sendo desenvolvidos pelos os docentes colaboradores, estagiários bolsistas do Programa de Bolsa de Inclusão Social (PBIS) e voluntários, por meio de uma coletânea de atividades. Na oficina ofertada foram apresentados os roteiros e os experimentos para posterior discussão, problematização e replicação dos mesmos em diferentes locais do litoral paranaense. Os professores puderam aplicar metodologia de coleta, extração e identificação de fauna do solo, que mostrou ser facilmente aplicável nas suas comunidades de inserção das escolas. Principalmente porque envolveu materiais alternativos e com baixo custo, além da característica da região litorânea que tem diversas áreas verdes que podem servir para estudo.

Todas as atividades de experimentação somente foram possíveis por causa do apoio e envolvimento dos estudantes estagiários bolsistas PBIS e voluntários, pois os mesmos auxiliaram desde o auxílio ao manuseio de equipamentos até o lanche servido nas oficinas.

Antes das oficinas foram realizados momentos teóricos com conversas para troca de experiências 
e apresentação de referenciais teóricos a respeito da divulgação científica, história e concepções da natureza da Ciência. Quanto à divulgação dos cursos e inscrições dos professores nas oficinas o procedimento foi, entrar em contato com o Núcleo Regional de Educação de Paranaguá (NRE) para a divulgação das oficinas nas escolas, com envio de cartazes juntamente com uma ficha de inscrição. E as inscrições ocorreram por ordem de envio de fichas, esgotadas após quatro dias de inscrição. $\mathrm{O}$ número de vagas ofertadas foi 25 para todas as escolas do litoral do Paraná. Depois das oficinas finalizadas as fotos das oficinas foram disponibilizadas e divulgadas à toda comunidade interna $\mathrm{e}$ externa mostrando as atividades desenvolvidas no curso de extensão e desenvolvidas nas duas oficinas

\section{Resultados e discussões}

Os cursos ofertados atingiram o público de 72 professores que trabalham as disciplinas de Ciências e Biologia e atuam em escolas públicas nos diferentes municípios do litoral paranaense como Paranaguá, Morretes, Antonina, Matinhos, Pontal do Paraná e Guaratuba. Estes números mostram que o curso de extensão ofertado atingiu metade dos docentes de Ciências e Biologia da região litorânea de acordo com os registros e relatos do NRE de Paranaguá.

Este fato mostra que é possível atingir os docentes para ofertar capacitação e formação contínua pois, a promoção da capacitação por meio de troca de experiências interfere positivamente na prática docente dos professores e pode refletir na qualidade de trabalho, evidenciado pelos relatos nos diferentes momentos das oficinas. Desta forma, os professores de Ciências e Biologia da rede pública do estado do Paraná puderam vivenciar atividades replicáveis com seus alunos nas suas escolas, a partir das atividades desenvolvidas nas oficinas. Levando até as suas comunidades a divulgação científica e a cultura científica mediada pelo diálogo e troca de experiências entre os docentes (Figura 1).

Neste sentido, para Tardiff (2000) os saberes docentes tem influência acadêmica onde se aproxima da produção científica do conhecimento, mas os professores quanto mais adquirem experiência influenciam e são influenciados pelos saberes escolares. E estes saberes traduzem um saber experiencial diferente do acadêmico e mais próximo do cotidiano que torna-se fundamental para manutenção da atualização e consequente qualidade da educação pública.).

A análise qualitativa dos relatos dos professores durante as oficinas mostraram que o uso do cinema e de atividades experimentais de campo, laboratório ou até mesmo em sala de aula, não é prática pedagógica cotidiana da maioria dos docentes de Ciências e Biologia da rede estadual de ensino no litoral do Paraná. Entendendo que a maneira como se ensina Ciências é diferente de como se produz o conhecimento cientifico Lopes (1999) e Freire-Maia (2000), se faz necessário estudar as diferentes possibilidades de abordagens metodológicas para a construção de uma cultura científica no nível escolar.

Outro ponto relevante do projeto esteve na relação do IFPR com a formação de professores que é uma exigência legal. E acredita-se que houve aproximação entre a rede estadual de educação pública com o IFPR. Pois, o curso ofertado é o segundo da história do Campus e o primeiro direcionado ao ensino de Ciências e Biologia. Especialmente para o litoral paranaense este tipo de atividade de extensão aproxima a comunidade externa ao IFPR e divulga o trabalho de muitos professores que vêm desenvolvendo atividades de pesquisa e extensão. Além disso, com a oferta das oficinas houve o atendimento do papel social que também é produzir e levar conhecimento científico à comunidade a qual o Instituto Federal do Paraná está inserido. Com isso, a proposta contemplou a aproximação entre o Instituto Federal do Paraná (IFPR) e a Secretaria de Estado da Educação do Paraná (SEED) por meio do Núcleo Regional de Educação Paraná de Paranaguá (NRE Paranaguá), que já era um parceiro do projeto, e indicou as escolas e professores partícipes dos cursos de formação continuada e a mediação entre as direções das escolas e o IFPR.

Muitos professores que participaram do curso atuam como docentes de Ciências e"ou Biologia em comunidades tradicionais de pescadores"extrativistas, indígenas e das ilhas da região litorânea do Paraná. E este era um dos focos do projeto que é a aproximação das comunidades tradicionais litorâneas. Um dos focos do projeto foi justamente a aproximação da universidade com as comunidades tradicionais litorâneas. Porém, há necessidade de aumentar essa aproximação, com o IFPR adotando o papel de incentivador e executor de propostas de formação continuada. Por isso, este curso de extensão deve ser ofertado mais vezes e com maior periodicidade tentando sempre melhorar a qualidade das atividades ofertas e buscar o envolvimento de mais professores da instituição com os professores da rede pública do estado do Paraná. 


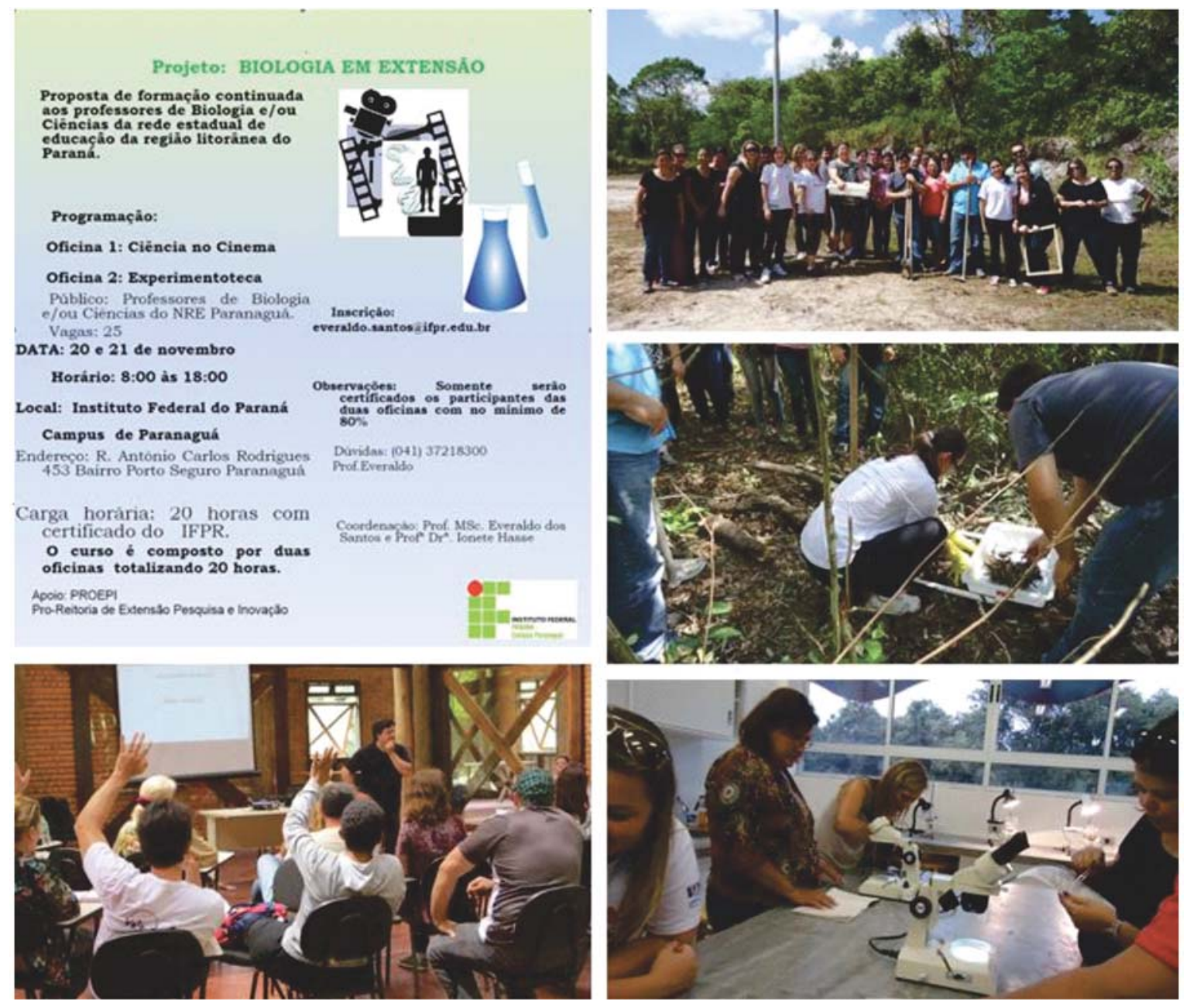

Figura 1 - Imagens acima demonstram algumas atividades desenvolvidas ao longo do trabalho feito com os professores: a) Cartaz de divulgação do curso; b) Atividade de campo com um grupo de professores(as); c) Grupo coletando solo para desenvolver atividade da experimentoteca com macrofauna invertebrada; d) Professores (as) desenvolvendo atividade em laboratório com extração da macrofauna edáfica do material coletado; e) Discussão dos principais resultados e alinhamento das atividades a serem desenvolvidas.

Fonte: dos autores.

Esta aproximação caracteriza uma forma diferente de capacitação dos professores onde não se dissocia ensino de aprendizagem na educação científica, corroborando com a visão de formação continuada de professores em parceria com estudantes. Nunes (2001) destaca que a formação de profissionais da educação deve ir além da capacitação que objetiva a transmissão de conhecimentos. A formação necessita mobilização dos professores para os diferentes contextos do seu trabalho cotidiano, buscando uma ruptura com a lógica disciplinar da universidade, onde se fragmenta os saberes, uma prática reforçada pelos livros didáticos.

Neste sentido, Lopes (1999) e Lopes (2007) defende que o currículo seja mais um produto cultural do que propriamente científico. Os resultados desta experiência de extensão apontam para isso, indicando que o uso do livro didático, orientador usual do trabalho docente, pode ser complementado pela seleção de conteúdos e pelo recorte cultural e contextual a partir da realidade local. Desta forma, a troca entre professores participantes do curso de extensão com seus saberes docentes a respeito das atividades de experimentação na educação científica, puderam exercitar a seleção de conteúdos e construção de um currículo voltado mais para a realidade cultural do litoral do Paraná.

\section{Conclusões}

Inicialmente o projeto de extensão atingiu o público alvo que foram os professores de Ciências e Biologia que atuam em escolas públicas estaduais nos diferentes municípios do litoral do Paraná. E 
aproximou o IFPR do NRE e consequentemente atingiu uma de suas missões que é a formação de professores. Entendendo que os saberes docentes, os saberes escolares assim como os conhecimentos científicos influenciam na prática pedagógica dos professores de Ciências e Biologia, procurou-se oportunizar um espaço e momento de intercâmbio no curso de formação continuada por meio de duas oficinas.

Pôde-se perceber ao final dos cursos ofertados em 2012 e 2014 que o desenvolvimento de atividades didático-pedagógicas, com a adoção de conteúdos que possam ser problematizados e contextualizados a partir do cinema e atividades de experimentação pode enriquecer a prática pedagógica dos professores participantes. E que há deficiência na oferta de atividades de formação continuada que colaborem no cotidiano das práticas escolares dos professores de Ciências e Biologia dos municípios litorâneos da rede estadual de educação do Paraná.

A partir destas oficinas pode-se concluir também que a reflexão e a discussão, geradas após as atividades e trocas entre os docentes, podem subsidiar a adoção de novas práticas metodológicas. De maneira que se aprimore o desenvolvimento de atividades que priorizem o saber científico, valorizando a cultura local, utilizando atividades de experimentação e Cinema para ensinar Ciências.

\section{Fontes de Financiamento}

Pro-Reitoria de Extensão Pesquisa, Pós-Graduação e Inovação PROEPPI/IFPR/CNPq apoio ao projeto concedendo bolsas de extensão por meio dos editais 017/2012 e 01/2014.

\section{Agradecimentos}

Ao Núcleo Regional de Educação de Paranaguá (NRE) da Secretaria de Estado da Educação do Paraná (SEED) pelo apoio e divulgação dos eventos de extensão junto às escolas. E especialmente à PROEPPI/IFPR/CNPq pela concessão de bolsas aos estudantes.

\section{Referências bibliográficas}

BONOTTO, D. M. Teaching radioactivity with the aid of the movie Madame Curie. XIV IOSTE, pg. 77 Conference program. Slovenia, 2010.

CACHAPUZ, A.; PRAIA, J.; JORGE, M. Da Educação em Ciência às orientações para o Ensino das Ciências: Um Repensar Epistemológico. Ciência E Educação, vol. 10, n. 3, 2004.

DUARTE, R.; ALEGRIA, J. Formação Estética Audiovisual: um outro olhar para o cinema a partir da educação. Educação \& Realidade, v. 33, n.1, 2008.

FIGUEIREDO, T. D Formação continuada para professores em metodologias educativas e tecnologias digitais. Caminho Aberto - Revista de Extensão do IFSC. ano 4. nº 6. 2017.

FREIRE-MAIA, N. A ciência por dentro. Petrópolis: Vozes, 2000.

GALIAZZI, M.C.; GONÇALVES, F. P. A natureza pedagógica da experimentação: Uma pesquisa na licenciatura em Química. Química Nova. Vol. 27, n. 2, 326-331, 2004.

LOPES, A.C. O livro didático nas políticas públicas de currículo. In: LOPES, A. C. Currículo e epistemologia. Ijuí: Unijuí, 2007.

LOPES, A.C. Conhecimento escolar e conhecimento científico: Diferentes finalidades, diferentes configurações. In: LOPES, A. C. Currículo e epistemologia. Ijuí: Unijuí, 2007.

LOPES, A.C. Questões para um debate sobre o conhecimento escolar. Revista do Laboratório de Ensino de História da UFF. Niterói. v.3, n. 3, 29-37, 1999.

LOUREIRO, R. Educação, Cinema e Estética: elementos para uma reeducação do olhar. Educação $\mathcal{E}$ Realidade, v. 33, n.1, 2008.

MARTINS, A. F. P. História e Filosofia da Ciência no Ensino: Há Muitas Pedras Nesse Caminho. Caderno Brasileiro de Ensino de Física, v.24, n.1, 2007. 
NUNES, C. M. F. Saberes docentes e formação de professores: um breve panorama da pesquisa brasileira. Educação \& Sociedade. n. 74, 2001. PACHECO, D. A experimentação no Ensino de Ciências. Ciência E Ensino, n. 2, Jun de 1997.

SCHEID, N. M.J. Contribuições do cinema na formação inicial de professores de Ciências Biológicas. Revista Vivência. v. 4, n. 6, 2008.

TARDIFF, M. Saberes profissionais dos professores e conhecimentos universitários. Revista Brasileira de Educação. n. 13, 2000.

TARDIFF, M. Saberes docentes e formação profissional. VOZES, Petrópolis, 2002.

Data de submissão: 27/10/2018. Data de aceite: 22/4/2019. 